\title{
Prevalence of residual excessive sleepiness in CPAP-treated sleep apnoea patients: the French multicentre study
}

\author{
J-L. Pépin*,\#, V. Viot-Blanc ${ }^{\tau,+}$, P. Escourrou ${ }^{\S}$, J-L. Racineux ${ }^{\dagger}$, M. Sapene**, P. Lévy*,\#, \\ B. Dervaux ${ }^{\# \#}, X$. Lenne ${ }^{\# \#}$ and A. Mallart ${ }^{\text {"ब }}$
}

ABSTRACT: The percentage of compliant continuous positive airway pressure (CPAP)-treated apnoeic patients that continue to experience residual excessive sleepiness (RES) is unknown.

RES was defined by an Epworth Sleepiness Scale (ESS) score of $\geqslant 11$. In total, 502 patients

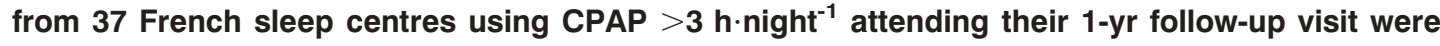
eligible.

ESS and polysomnographic data as well as symptoms, quality of life, depression scores and objective CPAP compliance at $1 \mathrm{yr}$ were collected. Overall, 60 patients remained sleepy on CPAP (ESS $14.3 \pm 2.5$ ) leading to a prevalence rate of RES of $12.0 \%$ (95\% confidence interval (CI) $9.1-$ 14.8). After having excluded associated restless leg syndrome, major depressive disorder and narcolepsy as confounding causes, the final prevalence rate of RES was $6.0 \%(95 \% \mathrm{Cl} 3.9-8.01)$. Patients with RES were younger and more sleepy at diagnosis. The relative risk of having RES was $5.3(95 \% \mathrm{Cl} 1.6-22.1)$, when ESS before treatment was $\geqslant 11$. Scores of emotional and energy Nottingham Health Profile domains were two times worse in patients with RES.

As 230,000 obstructive sleep apnoea patients are currently treated in France by continuous positive airway pressure, more than 13,800 of them might suffer from residual excessive sleepiness.

KEYWORDS: Continuous positive airway pressure, modafinil, prevalence, residual excessive sleepiness, sleep apnoea

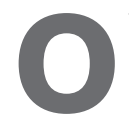

bstructive sleep apnoea syndrome (OSAS) is due to recurrent episodes of pharyngeal collapse occurring during sleep. It is a growing health concern affecting up to $5 \%$ of middle-aged males and females in the general population [1]. Excessive daytime sleepiness (EDS), fatigue and altered attention are the most frequent symptoms experienced by obstructive sleep apnoea (OSA) patients [2]. Several randomised controlled trials have established continuous positive airway pressure (CPAP) efficacy regarding sleepiness in OSAS [3-5]. The beneficial CPAP effect is obtained after only a few weeks of treatment, with quality of life returning to normal $[2,6]$.

A certain number of OSA patients continue to experience residual excessive sleepiness (RES) when using CPAP [7]. Low CPAP adherence, inadequate CPAP titration, insufficient sleep syndrome and undiagnosed coexisting sleep disorders are the most frequent explanations [8]. However, even after sleep hygiene improvement, adjustment of CPAP pressure and comorbid sleep pathologies have been ruled out, a proportion of regular CPAP users still experience RES. In this situation, stimulants have been demonstrated to be able to improve subjective and objective vigilance, and also quality of life [8-14]. Surprisingly, while appropriate pharmacological therapy is available, there are no data regarding the prevalence of RES in compliant CPAP-treated OSA patients.

Thus, the present authors sought to assess the prevalence of RES in compliant OSA patients treated with CPAP for $1 \mathrm{yr}$. Secondly, the current authors wished to determine whether these patients exhibited specific characteristics at OSA diagnosis, thereby establishing predictive factors for RES. The third objective was to determine whether particular quality of life alterations were associated with RES.

\section{METHODS}

The present cross-sectional study was conducted at 37 centres from 10 regions in France (13 centres in private practice and 24 in hospital sleep laboratories).
AFFILIATIONS

*HP2 Laboratory (Hypoxia

Pathophysiology), INSERM ERI 0017 EA 3745 Joseph Fourier University,

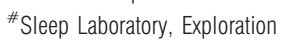

Fonctionelle Cardio Respiratoire (EFCR), University Hospital Grenoble,

- Sleep Unit, CHU Lariboisière, Paris, ${ }^{+}$Cephalon, Maisons-Alfort,

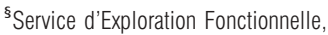
Hôpital Antoine Béclère, Clamart,

‘Laboratoire d' Exploration Fonctionelle Respiratoire et de Sommeil, CHU d'Angers, Angers,

${ }^{* *}$ Unité Sommeil et Vigilance

Polyclinique, Bordeaux-Cauderan,

\#\#CRESGE, and

"CHU Lille, Lille, France.

CORRESPONDENCE

J-L. Pépin

EFCR et Laboratoire du Sommeil Pole Rééducation et Physiologie INSERM ERI 17

CHU de Grenoble

BP $217-38043$

Grenoble Cedex 09

France

Fax: 33476765586

E-mail: JPepin@chu-grenoble.fr

Received:

February 042008

Accepted after revision:

February 022009

SUPPORT STATEMENT

The present study was sponsored by Cephalon (Maisons-Alfort, France).

STATEMENT OF INTEREST

A statement of interest for this study can be found at

www.erj.ersjournals.com/misc/ statements.dtl

European Respiratory Journal Print ISSN 0903-1936

Online ISSN 1399-3003 
The protocol complied with the Declaration of Helsinki and was reviewed and approved by the Institutional Review Board (Lille, France). None of the participants received compensation for their participation in the present study and all of them gave written consent.

\section{Study participants}

Patients suffering from OSAS with an apnoea/hypopnoea index (AHI) of $\geqslant 10$ before CPAP therapy and using CPAP $>3 \mathrm{~h} \cdot$ night $^{-1}$ for $1 \mathrm{yr}$ were eligible. Participants were asked to participate at the time of their $1 \mathrm{yr}$ follow-up visit (915 months of CPAP use was the accepted range). In France, this systematic visit is required for reimbursement by the health authorities and to assess CPAP adherence and efficacy. A mean CPAP use of $>3 \mathrm{~h} \cdot$ night $^{-1}$ and an improvement in symptoms are required for pursuing reimbursement of CPAP therapy. Each centre was asked to include all consecutive CPAP-treated patients attending the sleep centre who were using CPAP for $>3 \mathrm{~h} \cdot$ night $^{-1}$ based on the time using a mask as provided by the CPAP machine counters. RES was defined as an Epworth Sleepiness Scale (ESS) score of $\geqslant 11$. Exclusion criteria were shift work, chronic sleep deprivation, another respiratory disease requiring long-term oxygen therapy or other active clinically significant diseases.

The present authors estimated that a population of 60 patients exhibiting RES was required to determine predictive factors associated with residual sleepiness. At the time of the current study, no data were available in the literature about the prevalence of RES in CPAP-treated patients. As a prevalence of RES of $14 \pm 1.5 \%$ was anticipated, a sample size calculation of 500 was obtained.

\section{Collected data}

Pre-CPAP data

The ESS [15], anthropometric and polysomnographic data at diagnosis were obtained from the patient medical chart. AHI scores from nocturnal polysomnography (PSG) or simplified polygraphy without electroencephalogram recordings performed at diagnosis were collected. These recordings were analysed and scored at each individual centre. Effective pressures have been determined at each centre by manual titration under PSG or by Auto-CPAP titration procedures at home.

\section{Data at inclusion after $1 \mathrm{yr}$ of CPAP use}

The ESS, as well as anthropometric items, symptoms, quality of life and depression scales, were collected. CPAP, associated side-effects and objective compliance after 1 yr of CPAP use were taken into account. Comorbidities, alcohol intake, smoking and medication use were also recorded. Finally, the centres were asked to indicate whether other sleep disorders, such as restless legs syndrome and narcolepsy, were excluded clinically or by PSG.

Quality of life was assessed using the Nottingham Health Profile (NHP) scale [16], translated and validated in French [17]. The first part of the NHP was used, which includes 38 items exploring six dimensions of perceived health: energy, pain, sleep, physical mobility, emotional reactions and social isolation. For each item the answer was yes $(=1)$ or no $(=0)$. Each item was weighted and a final score was calculated for each dimension by adding the weighted answer of each item.
For each dimension, the score ranges from 0 (excellent perception of health) to 100 (very poor perception of health). The results of the NHP in CPAP-treated OSA patients with or without RES were compared with an untreated OSA population [6]. Major depressive episodes were identified using a specific module of the Mini International Neuropsychiatric Interview [18].

\section{Statistical analysis}

The normality of data distribution was assessed and continuous data are expressed as mean \pm SD. The relationship between RES and other characteristic variables were explored initially by a multiple correspondence analysis. In a second step, hierarchical ascendant clustering analysis allowed the creation of homogeneic clusters of patients with similar characteristics. Comparisons between patients with or without RES were made using the Chi-squared test for qualitative variables and using an unpaired t-test or Mann-Whitney test for continuous variables. Evolution under CPAP treatment was tested using the McNemar test for dichotomic variables and using a paired t-test or Wilcoxon test for continuous variables. A p-value $<0.05$ was considered as significant. The relative risk (RR) of having RES was calculated and is presented with confidence intervals (CIs).

\section{RESULTS}

\section{Prevalence rate of RES}

A total of 502 patients $(78 \%$ males, mean \pm SD age $59 \pm 11$ yrs, mean $\pm \mathrm{SD}$ body mass index (BMI) $31.9 \pm 5.9 \mathrm{~kg} \cdot \mathrm{m}^{-2}$ and mean \pm SD apnoeas/hypopnoeas $51 \pm 22 \cdot \mathrm{h}^{-1}$ of sleep) from 37 French sleep centres were included. Figure 1 shows the distribution frequency of the ESS scores after 1 yr of CPAP treatment in the studied population. For the whole group, the mean \pm SD ESS score was $5.9 \pm 4$.

In total, 60 out of the 502 patients exhibited RES on CPAP (ESS score of $14.3 \pm 2.5)$, leading to a crude prevalence rate of RES of $12.0 \%$ (95\% CI 9.1-14.8). Associated restless legs syndrome, major depression and narcolepsy were reported in $25 \%, 17 \%$

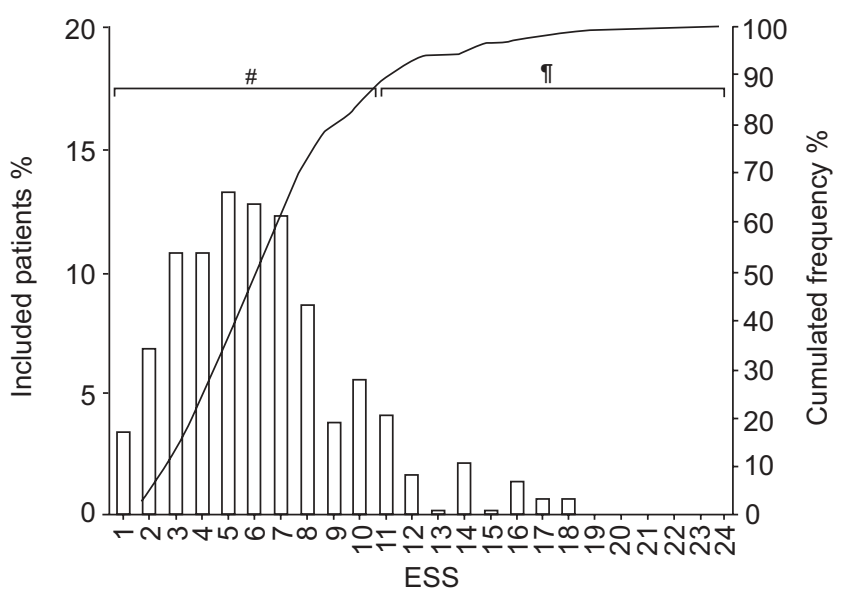

FIGURE 1. Distribution frequency of the Epworth Sleepiness Scale (ESS) scores after $1 \mathrm{yr}$ of continuous positive airway pressure (CPAP) use. Obstructive sleep apnoea CPAP users without $\left(^{\#}\right)$ or with (") residual excessive sleepiness as defined by an ESS of $\geqslant 11$ 
and $2 \%$ of the sleepy patient group versus $11 \%, 4 \%$ and $<1 \%$ in the nonsleepy OSA CPAP users, respectively $(\mathrm{p}<0.01$ for restless legs syndrome and major depression).

Hierarchical ascendant clustering analysis led to the identification of a cluster $(n=436)$ in which a majority of subjects did not present a suspicion of major depressive disorder $(90.4 \%$ without the disease), cataplexy (93.6\% without the disease), restless legs syndrome (76.4\% without the disease), mask leaks, residual events or poor CPAP compliance. In this cluster, the prevalence rate of RES decreased to $8.4 \%$ (95\% CI 5.9-10.8).

All patients presenting with restless legs syndrome, major depression and a suspicion of narcolepsy were discarded, as was an additional group of subjects documented by clinicians as taking medications influencing vigilance or having an insufficient CPAP to appropriately treat OSA. Overall, 30 individuals among the initial population of 502 had an ESS score of $>10$ without any known explanation or any associated disease, thus giving a prevalence rate of RES of $6.0 \%$ (95\% CI 3.9-8.0).

\section{Comparison of OSA CPAP users with or without RES}

As shown in table 1, patients with RES were on average 6 yrs younger and were sleepier at the time of diagnosis. There were no significant differences in sex, BMI or estimated sleep duration. Duration of CPAP machine use, side-effects and pressure levels were the same in both groups (table 1). There was no significant relationship between cardiovascular history, hypertension or diabetes and RES.

Figure 2 illustrates the changes in ESS scores in patients with an ESS value of $<11$ or $\geqslant 11$ at diagnosis. With CPAP treatment, the mean ESS value significantly decreased in both groups, but the prevalence of RES was 2.0 (95\% CI 0.4-5.8) and 10.8 (95\% CI 7.0-15.8), respectively $(p<0.0001)$.

\section{Predictive factors of RES}

The RR of RES was 5.3 (95\% CI 1.6-22.1; p<0.001) when the ESS score before treatment was $\geqslant 11$. Being younger than 55 yrs was also associated with a two-fold risk of suffering from RES on CPAP (RR 2.4; 95\% CI 1.1-5.6; $\mathrm{p}=0.02$ ).

\section{Consequences of RES on other outcomes}

Patients with RES compared with OSA patients without RES reported fatigue and unrefreshing sleep in 33\% versus $7 \%$ and $37 \%$ versus $5 \%$ ( $p<0.001$ for both), respectively. All NHP domains returned to close to normal values (fig. 3) in CPAP-treated OSA patients without RES. In contrast, mean scores of emotional and energy NHP domains were two times worse in patients with RES $(\mathrm{p}<0.003)$ versus CPAP-treated OSA patients without RES. In the RES patients, the mean value for energy domain did not differ to that usually found in severe untreated OSA.

\section{DISCUSSION}

To the present authors' knowledge, the current study is the first to address the prevalence of RES in CPAP-treated apnoeic patients. In a large group of 502 OSA patients using CPAP $>3 \mathrm{~h} \cdot$ night $^{-1}$, $12 \%$ continued to have an ESS of $>10$ after 1 yr of treatment. Even after having excluded possible confounding factors, $6 \%$ remained sleepy without any other explanation. RES significantly impacted on daily life as these patients had significantly more fatigue, unrefreshed sleep and a greater impairment in energy and emotional quality of life domain scores.

\section{Study limitations and strengths}

Two methodological issues regarding the present study deserve comment. First, the PSG methods, definitions of hypopnoea and scoring of respiratory events were not standardised across the participating centres. However, included patients had severe OSA and in this situation only small changes in the AHI scoring are expected from one centre to another. Secondly, effectiveness of therapy with respect to residual AHI while receiving CPAP was also assessed by different methods depending upon the participating centres. The patients could have benefited from complete PSG on CPAP or simply the detection of residual events as provided by the auto-CPAP devices used for CPAP titration without the assessment of sleep structure or fragmentation. This last method has been considered as adequate in previous studies in the field $[10,11]$.

The present authors acknowledged that measurements of objective sleepiness data would have strengthened the current study. However, RES on CPAP is systematically defined in the literature as a subjective complaint [19]. This subjective complaint is associated with an impaired quality of life and

\begin{tabular}{|c|c|c|c|c|}
\hline \multirow[t]{3}{*}{ TABLE 1} & \multicolumn{4}{|c|}{$\begin{array}{l}\text { Comparison between obstructive sleep apnoea } \\
\text { (OSA) patients using continuous positive airway } \\
\text { pressure (CPAP) for } 1 \text { yr with or without residual } \\
\text { excessive sleepiness (RES) in patients not } \\
\text { presenting with confounding factors of } \\
\text { sleepiness }\end{array}$} \\
\hline & & \multicolumn{2}{|c|}{ OSA CPAP users } & \multirow[t]{2}{*}{ p-value } \\
\hline & & $\begin{array}{c}\text { Without } \\
\text { RES }\end{array}$ & With RES & \\
\hline Age yrs & & $60 \pm 11$ & $54 \pm 12$ & 0.003 \\
\hline Male/female & & $80 / 20$ & $70 / 30$ & NS \\
\hline BMI $\mathbf{k g} \cdot \mathrm{m}^{-2}$ & & $32 \pm 6$ & $31 \pm 5$ & NS \\
\hline ESS scores & diagnosis & $12 \pm 5$ & $16 \pm 5$ & $<0.001$ \\
\hline Apnoeas/hyp & pnoeas $\cdot h^{-1}$ of sleep & $52 \pm 22$ & $40 \pm 17$ & 0.004 \\
\hline Estimated sl & p duration $h \cdot$ night $^{-1}$ & $7.6 \pm 1.5$ & $7.4 \pm 2.3$ & NS \\
\hline CPAP use $h$. & $\operatorname{ght}^{-1}$ & $6.5 \pm 2.9$ & $6.1 \pm 1.3$ & NS \\
\hline Mean pressu & level $\mathrm{cmH}_{2} \mathrm{O}$ & $10 \pm 2$ & $9 \pm 2$ & NS \\
\hline Side-effects & te $\%$ & 52 & 57 & NS \\
\hline Mouth dryn & & 32 & 33 & NS \\
\hline Noise & & 8 & 3 & NS \\
\hline Nasal intole & ance & 14 & 23 & NS \\
\hline Hypertensior & & 51 & 50 & NS \\
\hline Cardiovascu & r history \% & 20 & 13 & NS \\
\hline Type I diabe & s \% & 3 & 3 & NS \\
\hline Type II diabe & es $\%$ & 12 & 13 & NS \\
\hline \multicolumn{5}{|c|}{$\begin{array}{l}\text { After having discarded confounding factors (depression, restless legs } \\
\text { syndrome, medications and ineffective CPAP), the final comparison between } \\
\text { OSA with or without RES was performed in a group of } 407 \text { subjects. Data are } \\
\text { presented as mean } \pm \text { SD or } n \text {, unless otherwise stated. BMI: body mass index; } \\
\text { ESS: Epworth Sleepiness Scale; NS: nonsignificant. }{ }^{\#}: n=377 ; ~ \\
\text { ( } n=30 \text {. }\end{array}$} \\
\hline
\end{tabular}



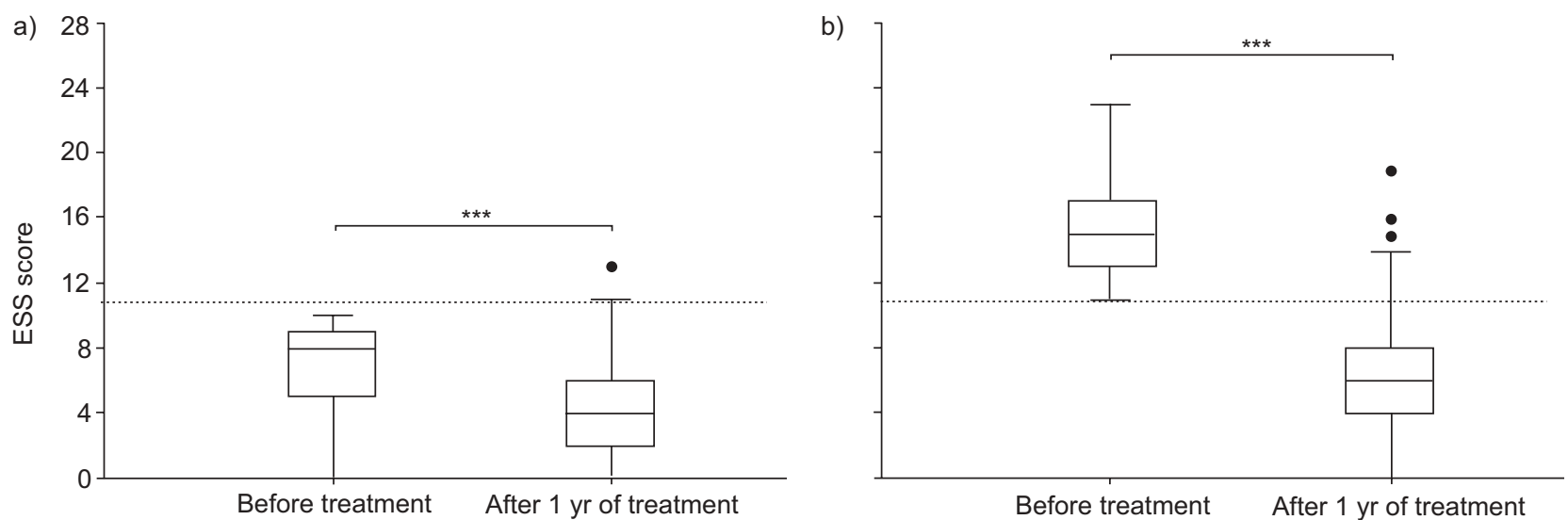

FIGURE 2. Evolution of Epworth Sleepiness Scale (ESS) scores after 1 yr of continuous positive airway pressure (CPAP) in patients with an ESS value a) $<11$ or b) $\geqslant 11$ at diagnosis (ESS at diagnosis was available in a subgroup of $n=361$ ). With CPAP treatment, the mean ESS value significantly decreased in both groups but the prevalence of residual excessive sleepiness was 2.0 (95\% confidence interval $(\mathrm{Cl})$ 0.4-5.8) and $10.8(95 \% \mathrm{Cl} 7.0-15.8)$, respectively $(\mathrm{p}<0.0001)$. …….. ESS 11. ***: $\mathrm{p}<0.001$.

psychological stimulants are recommended in this clinical situation by different consensus statements [20]. Objective sleepiness has been assessed in some pharmacological studies evaluating modafinil efficacy but, in these studies, inclusion criteria allowing the diagnosis of RES were based only on the ESS [12].

The current study included $>500$ patients with varied clinical practices reflecting the real life of sleep apnoea clinical management in France. Some centres were in the private sector whilst others were in public hospital practices either in teaching university hospitals or in district hospitals. Patients from 10 regions in France were also included, which was a representative sample with regard to places of residence, rural/urban ratio and socio-professional groups.

The present study design was a cross-sectional analysis after 1 yr of CPAP use that did not allow the documentation of a potential fall and raise phenomenon in ESS in these patients. However, a recent study showed that changes in the ESS in patients on CPAP are mainly limited to the first months of

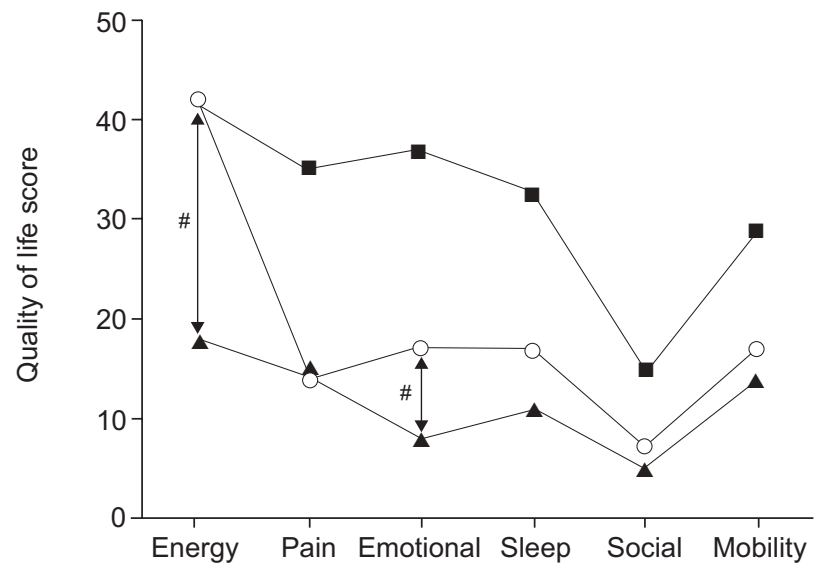

FIGURE 3. Quality of life in obstructive sleep apnoea (OSA)-treated patients with $(O ; n=30)$ or without $(\mathbf{\Lambda} ; n=377)$ residual excessive sleepiness in patients not presenting confounding factors of sleepiness. Untreated OSA patient values ( are presented according to [17]. ${ }^{\#:} p<0.003$.
CPAP treatment [21]. After 1 yr of CPAP use, the current patients were in a RES stable condition. Accordingly, for OSA patients with RES included in a pharmacological trial, those in the placebo group did not exhibit significant changes in their ESS over 12 weeks [12]. Taken together, these data suggest that a single ESS measurement at $1 \mathrm{yr}$ accurately measured RES prevalence and another strength of the present study was that the prevalence of RES was assessed "in a stable state" after 1 yr of treatment.

\section{Prevalence of RES}

In 2001, PACK et al. [11] underlined that the prevalence of RES in OSA patients receiving effective CPAP therapy was unknown and they recommended further studies. Indeed, none of the studies assessing the effects of vigilance stimulants on RES provided an assessment of the prevalence of RES as reflected by the number of CPAP-treated patients that had to be screened in order to enrol the study population [8-14]. However, it should be noted that in order to perform a study including 305 patients with RES, 42 US and UK participating centres were needed [12]. The need for so many centres suggests that RES is a rather rare condition. In a recent metaanalysis (14 randomised controlled trials including 706 patients) comparing effective CPAP versus sham CPAP or pills, ESS scores showed a mean decrease of 2.91 [3]. The mean ESS reduction was 4.75 in severe patients with an AHI $>30 \cdot h^{-1}$ of sleep and an ESS of $\geqslant 11$ at diagnosis [3]. This suggests that at least some CPAP users remained sleepy. However, in these randomised controlled trials, the participating patients were highly selected and the population of OSA with RES was not precisely described. In a retrospective clinical cohort, Guilleminault and Philip [22] showed that 182 (4.4\%) of the 4,129 patients remained sleepy despite treatment. This was particularly the case in morbidly obese subjects.

In the present study, a $12 \%$ RES prevalence decreasing to $6 \%$ was found when usual confounding factors were taken into account. The confounding factors that the current authors considered as significant were the same as those used as exclusion criteria in studies on the treatment of RES [8-14]. Depression is the primary cause of daytime hypersomnia in the general population [23] and it is likely to be a plausible 
explanation for RES in those included patients exhibiting major depression [24]. However, as RES is associated with impaired quality of life, depression could also have been linked to residual symptoms and complaints reported by the RES patients. The current authors also found a $25 \%$ prevalence of restless legs syndrome in CPAP user patients with RES. This is significantly greater than the prevalence reported in the French general population [25]. In clinical cohorts, 30\% of restless legs syndrome patients complain of EDS as assessed by an ESS score of $>10$ [26]. In the general population, subjects with restless legs syndrome symptoms had statistically more frequent EDS. However, this association was stronger only in subjects with daily $\left(7\right.$ days $^{*}$ week $\left.^{-1}\right)$ restless legs syndrome symptoms [27], which was not systematically the case in the present patients. Thus, the current authors have cautiously discarded OSA patients with potential confounding factors to provide a final prevalence of RES of $6 \%$. As not all depressive and restless legs syndrome subjects actually have sleepiness, the true RES related to treated OSA is potentially slightly higher.

\section{Predictive factors associated with RES}

None of the items related to CPAP machine efficacy or functioning were related to RES. The compliance with the device was high in OSA patients either with or without RES. The rate of side-effects and the level of pressure were also the same in both groups.

In recent studies based on large random samples of the general population, the primary determinants of subjective EDS were depression and metabolic disturbances (obesity or diabetes) [24]. In the present study, BMI and metabolic or cardiovascular history were at the same level in the two populations with or without RES.

RES was not related to a more severe sleep apnoea as measured by AHI at diagnosis or a shorter sleep duration subjectively reported by the patients.

OSA patients suffering from RES only demonstrated significantly younger age and greater sleepiness at diagnosis. It has been proposed that, in a subgroup of patients, OSAS per se may promote irreversible anoxic brain damage affecting the prefrontal cortex $[28,29]$. This hypoxic damage may underlie persistent sleepiness and cognitive dysfunction despite treatment. It remains unclear why one individual OSA patient may or may not develop this kind of lesion. The fact that the subgroup of OSA patients with RES was younger and sleepier at diagnosis with the same range of OSA severity compared with those without RES suggests that RES patients represent a subgroup with particular (genetically determined?) brain susceptibility to hypoxic exposure [30].

\section{Morbidity associated with RES}

The present study also supports the fact that RES has a significant impact on patient daily life. RES patients were not only sleepy but also demonstrated more fatigue, unrefreshing sleep and altered quality of life. Using the clinical global impression of severity (CGI-S), previous studies have already reported that patients with RES complain of being moderately ill $(60 \%)$ or even markedly ill (20\%) [11]. Regarding quality of life in OSA, before treatment, the most impaired domains when looking at an NHP evaluation were energy, emotional and sleep subscales $[6,16]$. As previously reported [6, 31, 32], these three dimensions markedly improved with CPAP in OSA without RES. In OSA patients with RES, energy domain remained the same as in untreated OSA patients and the emotional domain was also still significantly impaired. Randomised controlled trials using stimulants in RES patients have demonstrated a significant improvement both in terms of symptoms [11] and quality of life [9]. In particular, the activity level subscale of the functional outcomes of the sleep questionnaire, which corresponds to the energy domain of the NHP has been shown to be significantly improved by stimulants $[8,9]$.

\section{Conclusion}

In an unselected population of CPAP-treated OSA patients, the prevalence of RES was $\geqslant 6 \%$. As 230,000 OSA patients are currently treated in France by CPAP, it can be estimated that $>13,800$ of them still suffer from RES. Younger and sleepier patients at diagnosis are more prone to remain sleepy on CPAP and need a careful follow-up evaluation. RES is associated with persistent symptoms and alterations in quality of life. All these symptoms when persistent after careful exclusion of all possible confounding factors may justify RES treatment by stimulant agents [19].

There are some remaining open questions that need to be addressed in the research agenda, as follows. Does residual excessive sleepiness improve or get worse over several years? Does residual excessive sleepiness represent a risk factor for cardiovascular or other comorbidities? Is there any impact of pharmacological treatment on these outcomes?

\section{ACKNOWLEDGEMENTS}

The authors would like to thank X. Lenne and C. Deschaux who conducted the statistical analysis.

\section{REFERENCES}

1 Young T, Peppard PE, Gottlieb DJ. Epidemiology of obstructive sleep apnea: a population health perspective. Am J Respir Crit Care Med 2002; 165: 1217-1239.

2 Engleman HM, Douglas NJ. Sleep. 4: sleepiness, cognitive function, and quality of life in obstructive sleep apnoea/ hypopnoea syndrome. Thorax 2004; 59: 618-622.

3 Patel SR, White DP, Malhotra A, Stanchina ML, Ayas NT. Continuous positive airway pressure therapy for treating sleepiness in a diverse population with obstructive sleep apnea: results of a meta-analysis. Arch Intern Med 2003; 163: 565-571.

4 Giles TL, Lasserson TJ, Smith BH, White J, Wright J, Cates CJ. Continuous positive airways pressure for obstructive sleep apnoea in adults. Cochrane Database Syst Rev 2006; 3: CD001106.

5 Marshall NS, Barnes M, Travier N, et al. Continuous positive airway pressure reduces daytime sleepiness in mild to moderate obstructive sleep apnoea: a metaanalysis. Thorax 2006; 61: 430-434.

6 Lloberes P, Marti S, Sampol G, et al. Predictive factors of quality-of-life improvement and continuous positive 
airway pressure use in patients with sleep apnea-hypopnea syndrome: study at 1 year. Chest 2004; 126: 1241-1247.

7 Black J. Sleepiness and residual sleepiness in adults with obstructive sleep apnea. Respir Physiol Neurobiol 2003; 136: 211-220.

8 Schwartz JR, Hirshkowitz M, Erman MK, SchmidtNowara W. Modafinil as adjunct therapy for daytime sleepiness in obstructive sleep apnea: a 12-week, openlabel study. Chest 2003; 124: 2192-2199.

9 Dinges DF, Weaver TE. Effects of modafinil on sustained attention performance and quality of life in OSA patients with residual sleepiness while being treated with nCPAP. Sleep Med 2003; 4: 393-402.

10 Kingshott RN, Vennelle M, Coleman EL, Engleman HM, Mackay TW, Douglas NJ. Randomized, double-blind, placebo-controlled crossover trial of modafinil in the treatment of residual excessive daytime sleepiness in the sleep apnea/hypopnea syndrome. Am J Respir Crit Care Med 2001; 163: 918-923.

11 Pack AI, Black JE, Schwartz JR, Matheson JK. Modafinil as adjunct therapy for daytime sleepiness in obstructive sleep apnea. Am J Respir Crit Care Med 2001; 164: 1675-1681.

12 Black JE, Hirshkowitz M. Modafinil for treatment of residual excessive sleepiness in nasal continuous positive airway pressure-treated obstructive sleep apnea/hypopnea syndrome. Sleep 2005; 28: 464-471.

13 Roth T, White D, Schmidt-Nowara W, et al. Effects of armodafinil in the treatment of residual excessive sleepiness associated with obstructive sleep apnea/hypopnea syndrome: a 12-week, multicenter, double-blind, randomized, placebo-controlled study in nCPAP-adherent adults. Clin Ther 2006; 28: 689-706.

14 Hirshkowitz M, Black JE, Wesnes K, Niebler G, Arora S, Roth T. Adjunct armodafinil improves wakefulness and memory in obstructive sleep apnea/hypopnea syndrome. Respir Med 2007; 101: 616-627.

15 Johns MW. A new method for measuring daytime sleepiness: the Epworth Sleepiness Scale. Sleep 1991; 14: 540-545.

16 Fornas C, Ballester E, Arteta E, et al. Measurement of general health status in obstructive sleep apnea hypopnea patients. Sleep 1995; 18: 876-879.

17 Meslier N, Lebrun T, Grillier-Lanoir V, et al. A French survey of 3,225 patients treated with CPAP for obstructive sleep apnoea: benefits, tolerance, compliance and quality of life. Eur Respir J 1998; 12: 185-192.

18 Sheehan DV, Lecrubier Y, Sheehan KH, et al. The MiniInternational Neuropsychiatric Interview (M.I.N.I.): the development and validation of a structured diagnostic psychiatric interview for DSM-IV and ICD-10. J Clin Psychiatry 1998; 59: Suppl. 20, 22-33.

19 Santamaria J, Iranzo A, Ma Montserrat J, de Pablo J. Persistent sleepiness in CPAP treated obstructive sleep apnea patients: evaluation and treatment. Sleep Med Rev 2007; 11: 195-207.
20 Veasey SC, Guilleminault C, Strohl KP, Sanders MH, Ballard RD, Magalang UJ. Medical therapy for obstructive sleep apnea: a review by the Medical Therapy for Obstructive Sleep Apnea Task Force of the Standards of Practice Committee of the American Academy of Sleep Medicine. Sleep 2006; 29: 1036-1044.

21 Nguyen XL, Rakotonanahary D, Chaskalovic J, et al. Residual subjective daytime sleepiness under CPAP treatment in initially somnolent apnea patients: a pilot study using data mining methods. Sleep Med 2008; 9: 511-516.

22 Guilleminault C, Philip P. Tiredness and somnolence despite initial treatment of obstructive sleep apnea syndrome (what to do when an OSAS patient stays hypersomnolent despite treatment). Sleep 1996; 19: Suppl. 9, S117-S122.

23 Bixler EO, Vgontzas AN, Lin HM, Calhoun SL, VelaBueno A, Kales A. Excessive daytime sleepiness in a general population sample: the role of sleep apnea, age, obesity, diabetes, and depression. J Clin Endocrinol Metab 2005; 90: 4510-4515.

24 Baldwin DS, Papakostas GI. Symptoms of fatigue and sleepiness in major depressive disorder. J Clin Psychiatry 2006; 67: Suppl. 6, 9-15.

25 Tison F, Crochard A, Leger D, Bouee S, Lainey E, El Hasnaoui A. Epidemiology of restless legs syndrome in French adults: a nationwide survey: the INSTANT Study. Neurology 2005; 65: 239-246.

26 Holmes R, Tluk S, Metta V, et al. Nature and variants of idiopathic restless legs syndrome: observations from 152 patients referred to secondary care in the UK. J Neural Transm 2007; 114: 929-934.

27 Winkelman JW, Finn L, Young T. Prevalence and correlates of restless legs syndrome symptoms in the Wisconsin Sleep Cohort. Sleep Med 2006; 7: 545-552.

28 Morrell MJ. Residual sleepiness in patients with optimally treated sleep apnea: a case for hypoxia-induced oxidative brain injury. Sleep 2004; 27: 186-187.

29 Alchanatis M, Deligiorgis N, Zias N, et al. Frontal brain lobe impairment in obstructive sleep apnoea: a proton MR spectroscopy study. Eur Respir J 2004; 24: 980-986.

30 Tonon C, Vetrugno R, Lodi R, et al. Proton magnetic resonance spectroscopy study of brain metabolism in obstructive sleep apnoea syndrome before and after continuous positive airway pressure treatment. Sleep 2007; 30: 305-311.

31 Monasterio C, Vidal S, Duran J, et al. Effectiveness of continuous positive airway pressure in mild sleep apneahypopnea syndrome. Am J Respir Crit Care Med 2001; 164: 939-943.

32 Sanner BM, Klewer J, Trumm A, Randerath W, Kreuzer I, Zidek W. Long-term treatment with continuous positive airway pressure improves quality of life in obstructive sleep apnoea syndrome. Eur Respir J 2000; 16: 118-122. 